\title{
Metaldehyde poisoning of companion animals: a three-year retrospective study
}

\author{
Antonella De Roma ${ }^{1}$, Gianluca Miletti ${ }^{2}$, Nicola D'Alessio ${ }^{2}$, \\ Carmela Rossini ${ }^{1}$, Lucia Vangone ${ }^{2}$, \\ Giorgio Galiero ${ }^{2}$, Mauro Esposito ${ }^{1}$ \\ ${ }^{1}$ Chemistry Department, \\ ${ }^{2}$ Animal Health Department, \\ Istituto Zooprofilattico Sperimentale del Mezzogiorno, Portici, Napoli, 80055 Italy \\ antonella.deroma@izsmportici.it
}

Received: May 18, 2017

Accepted: August 23, 2017

\begin{abstract}
Introduction: Intentional and accidental poisoning of animals is often caused by readily available commercial pesticides, such as the molluscicide metaldehyde. A retrospective analysis of suspected metaldehyde poisonings between 2014 and 2016 in Italy was conducted. Material and Methods: Biological matrices were collected for toxicological analyses in the course of routine Institute activity. A total of 183 organs from dogs and cats and 49 pieces of bait, here specifically poisoned food used to lure animals, were analysed and the presence of metaldehyde was confirmed by gas chromatography coupled to mass spectrometry (GC/MS). Results: A high content of metaldehyde was demonstrated in the analysed samples from dogs and cats: $50(27.3 \%)$ animals were found positive for metaldehyde intoxication together with 17 pieces of bait. Conclusion: The study emphasised the need for the control of metaldehyde use by the veterinary service.
\end{abstract}

Keywords: dogs, cats, bait, metaldehyde, poisoning.

\section{Introduction}

Metaldehyde is a molluscicide which has been used to both attract and kill slugs and snails in agricultural settings since it was first registered in 1967 (9). It is a pure tetramer of acetaldehyde that forms colourless and tasteless white crystals, which give metaldehyde the appearance of a powder. The WHO has classified metaldehyde as a class II toxin, and therefore it can be moderately hazardous with acute health effects (17).

This molluscicide is readily available in mixed formulation and is often sold as blue-green pellets. Because of its wide and unrestricted commercial availability, it often plays the main role in intentional and accidental poisoning of domestic and wild animals. Although the oral lethal dose $\left(\mathrm{LD}_{50}\right)$ of metaldehyde is $100 \mathrm{mg} / \mathrm{kg}$ in $\mathrm{dogs}$ and $207 \mathrm{mg} / \mathrm{kg}$ in cats, severe effects can occur at much lower doses (15).

This phenomenon has been extensively reported worldwide: animals may be accidentally exposed to toxic agents in their environment or some pesticides may be voluntarily distributed by humans $(3,10)$. In both cases, exposure to pesticides is the primary cause of poisoning of domestic animals in Italy, accounting for $47.7 \%$ of total requests for confirmatory diagnosis in $2016(5)$.

To counter such risk, a new domestic regulation was submitted on June 13, 2016 by the Italian Ministry of Health in order to better define the rules on the prohibition of use and possession of poisoned baits and to align with EU Regulation 528/2013 on the exchange and use of biocidal products (12). As part of the preparatory work for the regulation, a three-year retrospective analysis was undertaken of suspected poisoned baits and cases of animals which had ingested or were suspected of having ingested metaldehyde.

This is a study of all requisitions submitted between 2014 and 2016 for diagnostic examination in suspected poisoning cases to the Istituto Zooprofilattico Sperimentale del Mezzogiorno (IZSM), the Italian Public Veterinary Health Institute, 
which represented a valuable source of data on the metaldehyde poisonings in the Campania and Calabria regions of Italy.

\section{Material and Methods}

Surveillance system and sample collection. From January 2009, with the enforcement of the first decree of the Italian Ministry of Labour, Health, and Social Policies regarding the prohibition of the use and possession of poisoned baits, an active surveillance system started. This placed more responsibility upon owners and veterinarians involved in animal poisoning cases. The owners are obliged to report animal poisoning cases to veterinary institutions. Bait samples and suspected poisoned animal tissues have to be sent to official control laboratories, such as the IZSM, for diagnostic and toxicological analysis. In cases of poisoned tissues and contaminated bait, it is compulsory to communicate the results to specified authorities. If the poisoning events are confirmed, the competent authority has to be notified and prosecutions may follow.

The data used in this study derived from the samples (carcasses, organs, and other biological materials) sent over the last three years for necropsy and/or toxicological examination to the IZSM, which performs the necessary tests as an institutional service. Samples were also pieces of bait or undefined materials which were found by the control authorities near animal remains or in other places. All the information about the sample, animal species, age, gender, circumstances of death, and place of discovery were furnished by owners or finders. Chemical analyses were performed on 49 suspected bait samples and samples of the liver, stomach, and gastric contents of $101 \mathrm{dogs}$ and 33 cats.

Necropsy. The necropsies were performed by the veterinary unit of the IZSM after the registration of the sample. During the examination all viscera were evaluated and photographed. All information obtained during the veterinary diagnostic investigation was registered. Samples of selected organs (liver, stomach, and intestine) and gastric contents were transferred into a specific plastic container and maintained at $-20^{\circ} \mathrm{C}$ until the toxicological analysis.

Toxicological analysis. The analytic methodology used, developed, and validated in the laboratories of the Department of Chemistry at the IZSM combines conventional solid-liquid extraction of the metaldehyde from the sample with gas chromatography-mass spectrometry detection (GC/MS). A standard solution of metaldehyde (Chem Service, USA) at a concentration of $100 \mathrm{mg} / \mathrm{L}$ was prepared by dissolving $10 \mathrm{mg}$ of the molluscicide powder in $10 \mathrm{~mL}$ of chloroform (Carlo Erba Reagenti SPA, Italy) using a volumetric flask. These solutions were stable when stored at $4^{\circ} \mathrm{C}$ for up to four months. Working standard solutions at concentrations of 0.1 , 1 , and $5 \mathrm{mg} / \mathrm{L}$, used for instrumental calibration, were freshly prepared in each analytical session by dilution of $100 \mathrm{mg} / \mathrm{L}$ solution in chloroform. The blank samples necessary for method optimisation were selected from among tissue samples of domestic animals negative for metaldehyde after diagnostic and analytic examinations. Fortified samples at a concentration of $1 \mathrm{mg} / \mathrm{kg}$ were prepared by spiking a blank dog liver sample $(2.0 \mathrm{~g})$ with $200 \mu \mathrm{L}$ of $100 \mathrm{mg} / \mathrm{L}$ standard solution prior to removal.

A total of $2 \mathrm{~g}$ of homogenised sample was treated with $35 \mathrm{~mL}$ of chloroform and $20 \mathrm{~g}$ of anhydrous sodium sulfate (Carlo Erba Reagenti SPA, Italy) in a $100 \mathrm{~mL}$ flask and shaken by vortex mixer for $120 \mathrm{~min}$. The resulting mixture was filtered by gravity using a paper filter (Whatman International Ltd., UK) supported by a glass funnel into a volumetric flask of $50 \mathrm{~mL}$ and then immediately injected for GC/MS analysis.

Chromatographic analysis was performed on a commercial Trace GC Ultra system (Thermo Fisher Scientific Inc., USA) coupled with a DSQ II mass spectrometer and Xcalibur software (both Thermo Fisher Scientific Inc., USA) for capture and elaboration of data. The GC system was equipped with an Elite 5MS column (PerkinElmer Inc., USA) $(30 \mathrm{~m} \times 0.25 \mathrm{~mm})$ operating with electron energy at $70 \mathrm{eV}$, source temperature at $280^{\circ} \mathrm{C}$ and transfer line at $250^{\circ} \mathrm{C}$. The flow rate of helium gas was $1 \mathrm{~mL} / \mathrm{min}$, and the injection volume was $1.0 \mu \mathrm{L}$.

The analytical procedure resulted in a three-fold dilution of metaldehyde, evaluated against the concentration of analyte in the specimen. The molluscicide was detected with a retention time of $6.44 \mathrm{~min}$ and a specific ratio of the four diagnostic ions of (m/z 45, 87, 89, 90) (Fig. 1).

\section{Results}

The analysis of several samples suspected of containing metaldehyde was carried out. Real samples were sent to the IZSM between 2014 and 2016 because they were suspected to be contaminated with molluscicide. Within a total of 183 samples, 50 cases were confirmed and the presence of the metaldehyde was also detected in 17 bait samples. As shown in Fig. 2, dogs were more affected by this intoxication.

Signs of metaldehyde toxicosis may begin after a few minutes or up to three hours after ingestion (8). As reported by veterinarians, $56 \%$ of the analysed cases (28/50) developed clinical symptoms (the outcome of the remaining 22 cases was unknown). The most common effects reported in animals were convulsions $(30 \%)$, tremor $(24 \%)$, hypersalivation (22\%), vomiting (18\%), and incoordination (16\%) (Table 1). 
Only in a few cases (11), a pharmacological therapy was applied to those animals that were found alive by their owners or by the authorities: hydrogen peroxide or apomorphine to induce emesis and activated charcoal with sorbitol or sodium sulphate to reduce absorption of the toxin from the gastrointestinal tract. There is no antidote for metaldehyde poisoning, so treatment is aimed at controlling clinical signs until the toxin is eliminated from the body (14). In our cases, in spite of the therapy, it was not possible to prevent the death of the animal, probably because the therapy was not promptly applied due to a late diagnosis of the poisoned animal. For all the other animals, already dead at the moment of their discovery, necropsy was performed. Although lesions associated with metaldehyde toxicosis in dogs or cats are relatively nonspecific and are mainly haemorrhages in the thoracic cavity, lesions in the lung parenchyma and peritoneal cavity have been observed.

Table 1. Signs reported in symptomatic dogs and cats with confirmed metaldehyde poisoning

\begin{tabular}{lll}
\hline Clinical effects & Dogs & Cats \\
\hline Hyperaemia of mucosa & 6 & \\
Vomiting & 9 & \\
Tremor & 10 & 2 \\
Convulsions & 13 & 2 \\
Tachypnea & 6 & \\
Hypersalivation & 10 & 1 \\
Blood loss from orifice & 3 & \\
Restlessness & 2 & \\
Incoordination & 7 & 1 \\
Tachycardia & 6 & \\
Diarrhoea & 3 & \\
\hline
\end{tabular}

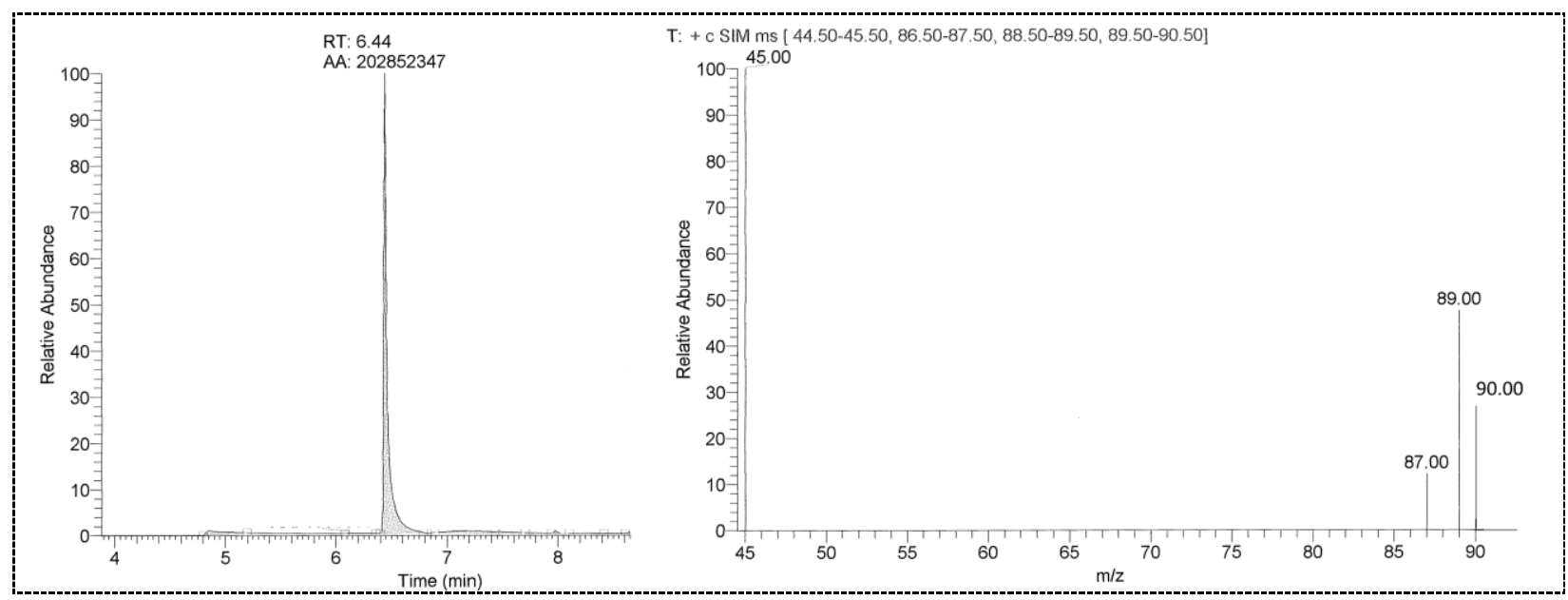

Fig. 1. GC/MS methaldehyde retention time and four diagnostic ions (m/z 45, 87, 89, 90)

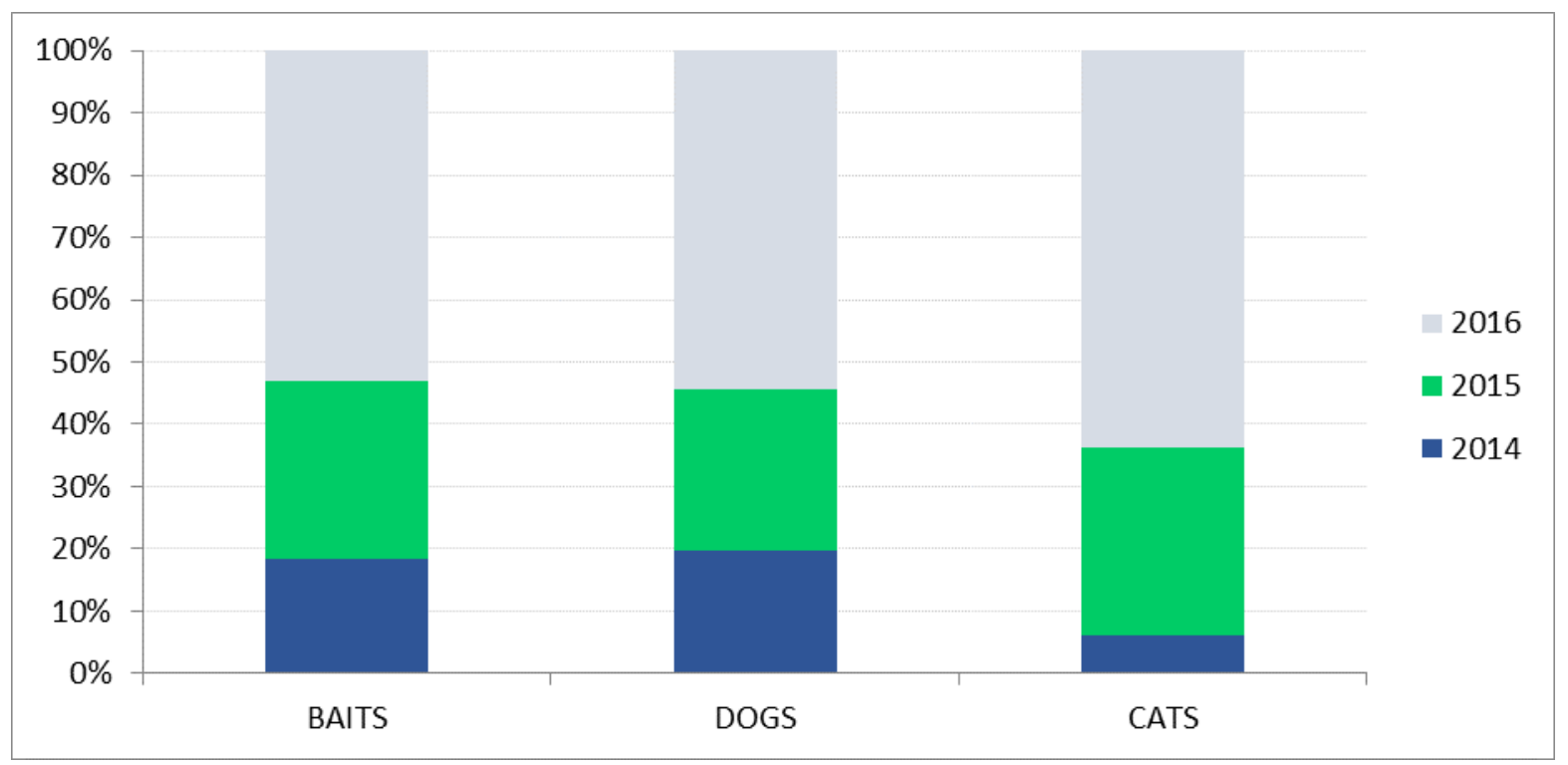

Fig. 2. Percentage distribution of the typology of all analysed samples over the three-year period (2014-2016) 


\section{Discussion}

This paper presents data from dog and cat poisoning and poisoned baits recovery episodes registered in the Campania and Calabria regions of Italy over a period of three years. In bait samples, in the digestive tract, and even in some cases in the stool, the molluscicide was macroscopically evident because it appeared with the characteristic blue colouration of the commercial formulation (Fig. 3).

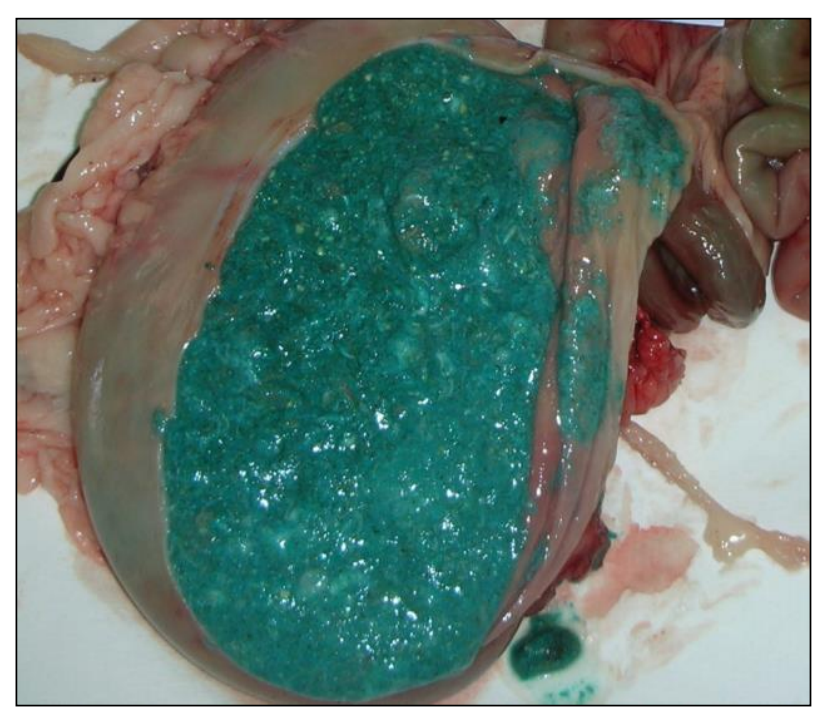

Fig. 3. Dog's gastric content full of metaldehyde

The case of the organic matrices was different because it was not easy to find the greenish colour of the metabolised bait. Furthermore, the blue colouration of the matrices, above all baits, could also be due to the use of anticoagulants, such as bromadiolone or brodifacoum, which give similar clinical signs, or to the accidental ingestion of copper sulphate, a chemical compound widely used around the world as a fungicide. Therefore, macroscopic examination alone may not allow a definitive diagnosis without the appropriate laboratory analysis.

Analysis of metaldehyde poisoning confirmation request data between 2014 and 2016 involved all samples collected. As shown in Fig. 2, the percentage of enquiries about metaldehyde ingestion gradually increased over time and peaked in 2016. The lower incidence of calls concerning cats may be attributed to the more prudent feeding habits characterising this species (such as the feline mistrust of offered food) together with their tendency to isolate themselves when sick, as was already observed by Albo and Nebbia (1).

Of the 67 positive specimens, the majority occurred in two different periods, between January and February (17 cases) and between the summer months of June and August (24 cases). While the reason for the peak in the winter period is not clear, a common cause of pet poisoning in the summer months could be the improper use or application of molluscicide products. In fact, between May and July, the region's weather is usually warm and wet and typically slug and snail activity is high, therefore there could be a larger use of metaldehyde, in line with what was already observed in the UK (2).

The $46.5 \%$ of the samples came from investigations requested of the IZSM laboratories by private citizens reporting, through the Local Health Units or prosecuting authorities, or as result of surveys carried out in private or urban public areas. Within the positive cases, $47 \%$ were due to a wilful intent, as suggested by the requesters: these events may correlate with relational problems of the animal owners with neighbours or be born of an individual's insane and unreasonable hostility toward animals. This could be confirmed by the fact that $26 \%$ of these positive cases derived from a second survey in the same area, providing indication of potential malicious use of this pesticide. Contrary to the fact reported for the suspected endosulfan poisonings analysed by the IZSM between 2013 and 2015 (7), where almost all samples came from Calabria, Campania was confirmed to be the region most contaminated by metaldehyde.

Metaldehyde toxicity has been reported in many species including cats, cattle, sheep, horses, and birds $(3,11)$. Canine exposure occurs frequently and has been reported in Europe $(6,16)$, North America (8), and Israel (18). Comparing the number of events registered in our study to those detected in other Italian regions, it is possible to assume that the number of confirmed metaldehyde poisonings is similar. A recent study reported a total of 171 positive cases for this molluscicide, analysing the distribution of the phenomenon in the north-eastern Italian regions during a seven-year period (4). If compared with results from other countries, the number of positive samples is lower than those reported by Bates et al. (16) in the UK (a mean value of 31 cases per year), but significantly higher than results reported in a six-year retrospective study in Austria (39 positive cases between 1999 and 2004).

All regulatory measures to protect domestic animals and wildlife, to regulate hunting activities, and to definitively eradicate the unfortunate scourge of poisoning bring the need to raise citizen awareness to the forefront. To this end, the Italian ordinance concerning "Rules on the prohibition of use and possession of bait or poisoned bait" of December 18, 2008 was enacted in 2016 (13). It aims to monitor poisonings and recognise the places and most frequently used poisons, and as the ultimate objective to advance any police investigations to identify the culprits, for which administrative and criminal penalties are provided.

There are no pet-safe slug and snail pesticides, therefore preventing ingestion of these products is crucial. Moreover, the data collected and the geographical identification of high-risk areas is an 
important prevention system, which can provide useful support for further investigations. At the same time, it is crucial that veterinarians and analysts be aware of the most widely used toxic agents and new emerging pesticides.

Conflict of Interests Statements: The authors declare that there is no conflict of interests regarding the publication of this article.

Financial Disclosure Statement: The authors declare that this study was financed by statutory activity.

Animal Rights Statement: The authors declare that the experiments on animals were conducted in accordance with local Ethical Committee laws and regulations as regards care and use of laboratory animals.

\section{References}

1. Albo A.G., Nebbia C.: Incidence of poisonings in domestic carnivores in Italy. Vet Res Commun 2004, 28, 83-88.

2. Bates N.S., Sutton N.M., Campbell A.: Suspected metaldehyde slug bait poisoning in dogs: a retrospective analysis of cases reported to the Veterinary Poisons Information Service. Vet Rec 2012, 171, 324-329.

3. Berny P., Caloni F., Croubels S., Sachana M., Vandenbroucke V., Davanzo F., Guitart R.: Animal poisoning in Europe. Part 2: companion animals. Vet J 2010, 183, 255-259.

4. Bille L., Toson M., Mulatti P., Dalla Pozza M., Capolongo F., Casarotto C., Ferrè N., Angeletti R., Gallocchio F., Binato G.: Epidemiology of animal poisoning: an overview on the features and spatio-temporal distribution of the phenomenon in the northeastern Italian regions. Forensic Sci Int 2016, 266, 440-448.
5. Caloni F., Cortinovis C., Rivolta M., Davanzo F.: Suspected poisoning of domestic animals by pesticides. Sci Total Environ 2016, 539, 331-336.

6. Campbell A.: Metaldehyde poisoning of dogs. Vet Rec 2008, 163,343

7. De Roma A., Rossini C., Riverso C., Galiero G., Esposito M.: Endosulfan poisoning in canids and felids in the Calabria Region of Southern Italy. J Vet Diagn Invest 2017, 29, 122-125.

8. Dolder L.K.: Metaldehyde toxicosis. Vet Med 2003, 98, 213-215.

9. EPA. Environmental Protection Agency. "EPA Reregistration Eligibility Decision (RED) for Metaldehyde". July 27, 2016.

10. Guitart R., Croubels S., Caloni F., Sachana M., Davanzo F., Vandenbroucke V., Berny P.: Animal poisoning in Europe. Part 1: farm livestock and poultry. Vet J 2010, 183, 249-254.

11. Guitart R., Sachana M., Caloni F., Croubels S., Vandenbroucke V., Berny P.: Animal poisoning in Europe. Part 3: wildlife. Vet J 2010, 183, 260-265.

12. Italian Ministerial Decree of 13 June 2016. Rules on the prohibition of use and possession of bait or poisoned bite. Italian Official Journal, no. 165, July 16, 2016.

13. Italian Ministerial Decree of 18 December 2008. Rules on the prohibition of use and possession of bait or poisoned bait. Italian Official Journal, no. 13, January 17, 2009.

14. Kitagaki J.M.: Toxicology brief: metaldehyde toxicosis in dogs. Vet Techn 2013, 34, n. 3, E1-E4.

15. Richardson J.A., Welch S.L., Gwaltney-Brant S.M., Huffman J.D., Rosendale M.E.: Metaldehyde toxicoses in dogs. ASPCA Animal Poison Control Center Urbana, Illinois, 2003, $25,376-380$

16. Wang Y., Kruzik P., Helsberg A., Helsberg I., Rausch W.D.: Pesticide poisoning in domestic animals and livestock in Austria: a 6-year retrospective study. Forensic Sci Int 2007, 169, 157-160.

17. WHO. The WHO recommended classification of pesticides by hazard and guidelines to classification. Germany, 2009.

18. Yas-Natan E., Segev G., Aroch I.: Clinical, neurological and clinicopathological signs, treatment and outcome of metaldehyde intoxication in 18 dogs. J Small Anim Pract 2007, 48, 438-443. 